\title{
Financiamiento público para partidos políticos y su reflejo en el desarrollo nacional, perspectiva comparada Argentina - México
}

\section{POR JOSÉ LUIS LEAL ESPINOZA $(*)$, CECILIA SOLEDAD CARRERA $(* *)$ $Y$ DANIELA JUDITH MONTALVO HERRERA $(* * *)$}

\author{
Sumario: I. Sistema de partidos.- II. Caso México - Argentina: parti- \\ dos políticos en la Constitución.- III. Financiamiento.- IV. Metodolo- \\ gía.- V. Resultados.- VI. Conclusiones.- VII. Bibliografía.
}

Resumen: el sistema democrático se ha configurado como la forma de gobierno más aceptable a nivel mundial; dicho sistema requiere para funcionar una serie de factores que fortalecen y legitiman la democracia, siendo uno de ellos por excelencia los partidos políticos, instituciones que con el ir y venir del desarrollo integral del Estado, han ganado terreno tanto en obligaciones como en derechos, como el financiamiento público que constituye una carga económica para el erario público, que no precisamente se refleja en un crecimiento en la calidad de vida de la ciudadanía, toda vez que el financiamiento público debería ser utilizado para que quienes aspiren a cargos públicos cuenten con los medios suficientes para contender en una elección y quien resulte ganador, ejecute su plataforma electoral, destinada a groso modo a impulsar el desarrollo del Estado y elevar la calidad de vida de la ciudadanía.

(*) Dr. en Filosofía (PhD) con especialidad en Derecho Constitucional y Derechos fundamentales, Universidad de Alicante, España. Esp. en Justicia Constitucional y Argumentación Jurídica, Universidad de Castilla La Mancha, España. Catedrático Investigador y Vicedecano de Investigación y Posgrado, Facultad de Ciencias Políticas y Sociales, Universidad Autónoma de Coahuila, México. Miembro del Sistema Nacional de Investigadores Nivel I, Consejo Nacional de Ciencia y Tecnología de México.

(**) Abogada. Notaria, Universidad Blas Pascal. Esp. en Derecho Judicial y de la Judicatura, Universidad Católica de Córdoba. Diplomada en Derechos Humanos con mención en Acceso a la Justicia, Universidad Católica de AUSJAL, IIDH y Universidad Católica de Córdoba. Diplomada en Gestión, Mediación y Resolución de Conflictos, Universidad Blas Pascal. Diplomada en Derecho Procesal Civil, Universidad Blas Pascal. Adscripta a la Cátedra de Derecho Político, Facultad de Derecho, Universidad Nacional de Córdoba. Adscripta a la Cátedra de Derechos Reales, Universidad Blas Pascal.

(***) Politóloga, Magíster en Gestión Municipal y Doctoranda en Relaciones Internacionales, Negocios y Diplomacia, Facultad de Ciencias Políticas y Administración Pública. Universidad Autónoma de Nuevo León. México. Investigadora adscripta, Facultad de Ciencias Políticas y Relaciones Internacionales. Universidad Autónoma de Nuevo México. 
Palabras claves: democracia - partidos políticos - desarrollo nacional - estudios comparados

Public financing for political parties and its reflection in national development, comparative perspective Argentina - México

Abstract: the democratic system has been established as the most acceptable form of government worldwide. This system requires to function a series of factors that strengthen and legitimize democracy, one of them being par excellence the political parties, institutions that with the coming and going of the integral development of the State, have gained ground in both obligations and rights, such as public financing that constitutes an economic burden for the public treasury, which is not precisely reflected in a growth in the quality of life of citizens, since Public financing should be used so that those who aspire to public office have sufficient means to contest an election and whoever is the winner, executes their electoral platform, designed in a broad way to promote the development of the State and raise the quality of life of the citizenship.

Keywords: democracy - political parties - national development - comparative studies

\section{Sistema de partidos}

\section{I.1. Partidos políticos}

\section{I.1.1. Definición}

Desde Duverger (2002) hasta Panebianco (2009), las definiciones sobre los partidos políticos coinciden en establecerlos como organizaciones que buscan el poder, constituyéndose como vehículos para que la ciudadanía exprese su voluntad en las elecciones.

En opinión de Cárdenas (2012) es difícil hablar de democracia en los tiempos que corren sin considerar a los partidos políticos, pues ellos son los principales articuladores y aglutinadores de los intereses sociales, siendo el medio para expresar tanto los intereses nacionales y particulares; por tanto, los partidos políticos en condiciones de una lucha política en igualdad de oportunidades son los mejores catalizadores, propiciadores y garantes de la democracia.

En el mismo tema, Basave (1982) asegura que los partidos políticos no pueden dejar de existir, en toda verdadera democracia, además de que prescindir de ellos es equivalente a prescindir de la representación.

Burke apuntó, poco más tarde, que los partidos son un ingrediente inseparable de todo gobierno libre. Y desde Burke, ningún demócrata duda sobre el deber de 
admitir la licitud de los partidos políticos y aún la convivencia de la oposición. El partido político es una pieza fundamental de la democracia que no puede ignorar el legislador (Burke, citado por Basave, 1982, p. 23).

De acuerdo con la doctrina que en materia de partidos políticos se sostiene en México, destacamos la aportación del jurista Orozco Henríquez, respecto de que "son organizaciones de ciudadanos que se han agrupado alrededor de una ideología común, con el propósito de construir puentes de acceso ciudadano a los poderes públicos del Estado" (Orozco y Vargas, s/f, p. 586).

En el ámbito de las instituciones públicas y privadas que realizan fines públicos, podemos destacar lo señalado por Morgan (1986) sobre las organizaciones sociales, ya que estas, por el hecho de estar conformadas por grupos de personas no son estáticas o rígidas, no se pueden concebir como máquinas en las que se desarrollan procedimientos y actividades para lograr objetivos, por lo que, entenderíamos que la interacción entre organizaciones sociales y públicas es el ejemplo más evidente de sistemas complejos, de acuerdo con García (2006).

\section{I.1.2. Objeto}

En un sistema democrático, los partidos políticos juegan un papel primordial, pues actúan como el medio idóneo, en nuestro tiempo, para canalizar y simplificar la opinión diversa que requiere representación en el gobierno. Es posible que esta canalización y simplificación traicione, en mayor o menor grado, el principio de exacta representación de todas las opiniones (Fernández, 1985, p. 259).

Una opinión diferente la aporta Paoli (2012), cuando de forma directa establece que los partidos son órganos auxiliares del Estado, destinados en primera instancia para promover la participación ciudadana en la vida democrática, en las decisiones públicas, en la integración de la representación nacional y en la formación del poder público.

Es impensable que la totalidad la población de un Estado opine de una misma forma; así tenemos partidos políticos que representan a grupos pequeños de la sociedad; las opiniones son muy variadas en relación con estos grupúsculos, que poseen una representación numérica muy pequeña en el parlamento y no parecen capaces, pues, de desempeñar un papel gubernamental oposicionista importante. Unos ven en ellos una fuente de división y de confusión lamentable y hacen todo lo posible por hacerlos desaparecer; otros les reconocen un papel de amortiguadores útiles (Duverger, 2002, p. 316).

A manera demostrativa, se sostiene que la utilización de varias fuentes doctrinales como Basave, son pertinentes, idóneas e ilustrativas para estructurar el 
argumento central de las funciones de los partidos en las democracias contemporáneas de acuerdo con su análisis de autores como Duverger, Sartori y Panebianco, en afán de hacer una breve síntesis de su labor al estudiar los aspectos sociales e institucionales de ellos.

\section{Ilustración 1. Funciones de los partidos en las democracias}

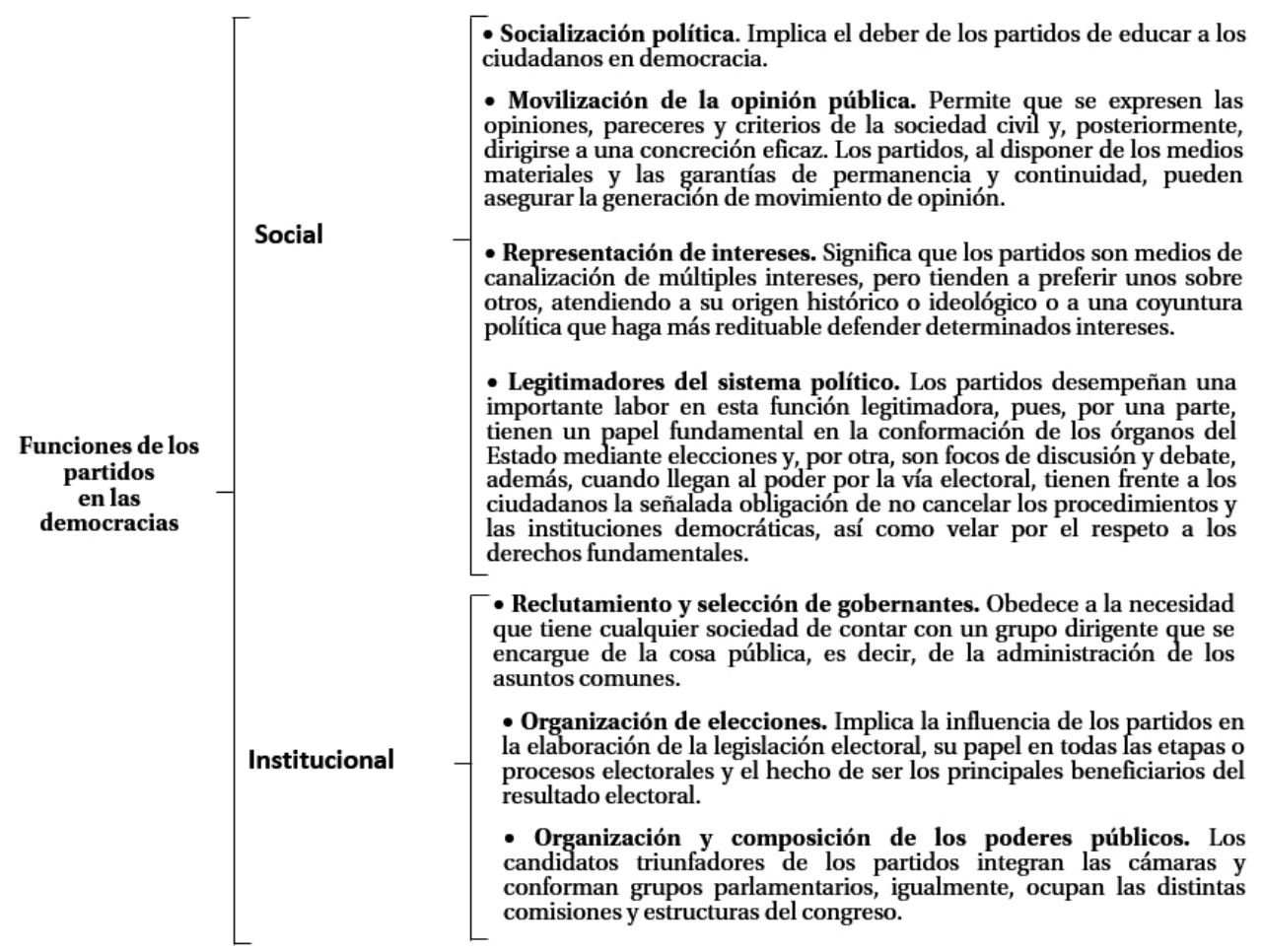

Fuente: elaboración propia con base en Basave (1982).

\section{I.2. Marco constitucional}

Aunado a lo que los estudiosos en la materia han definido como partido político, cada Estado Nación ha establecido dentro de su marco normativo no solamente su definición, sino que ha regulado su creación, funcionamiento, método de financiamiento e incluso algunos países como México han regulado parte de la vida interna del partido.

De forma general, y con el objeto de determinar la importancia que los Estados democráticos les conceden a los partidos políticos en la Ilustración 2, podemos observar la definición que cada uno le otorga a estas instituciones, partiendo del hecho que es justamente la definición de la que se parte para su regulación. 
Por una parte:

(...) es comúnmente aceptado que el origen y desarrollo de los partidos está en íntima conexión con el origen y desarrollo de la democracia parlamentaria liberal. Concepción que, a partir de la segunda guerra mundial, se generalizará sin ningún obstáculo - como reacción al fascismo derrotado- y que Duverger sabrá extenderla ampliamente. El Estado liberal, lo que los italianos suelen denominar 'Estado de democracia' clásica se asienta, por su naturaleza pluralista, sobre el funcionamiento regular de los partidos, entendidos, implícita o explícitamente, como piezas fundamentales del sistema (Ruffia, 1987, p. 216).

Dicha reflexión se encuentra orientada y armonizada conforme a los criterios razonados por parte del Tribunal Constitucional Alemán y enunciados sus principios en las sentencias del Tribunal Constitucional Español, concretamente en las sentencias paradigmáticas de la ilegalización y posterior legalización de EH-Bildu.

\section{Ilustración 2. Definición de los partidos políticos en las constituciones}

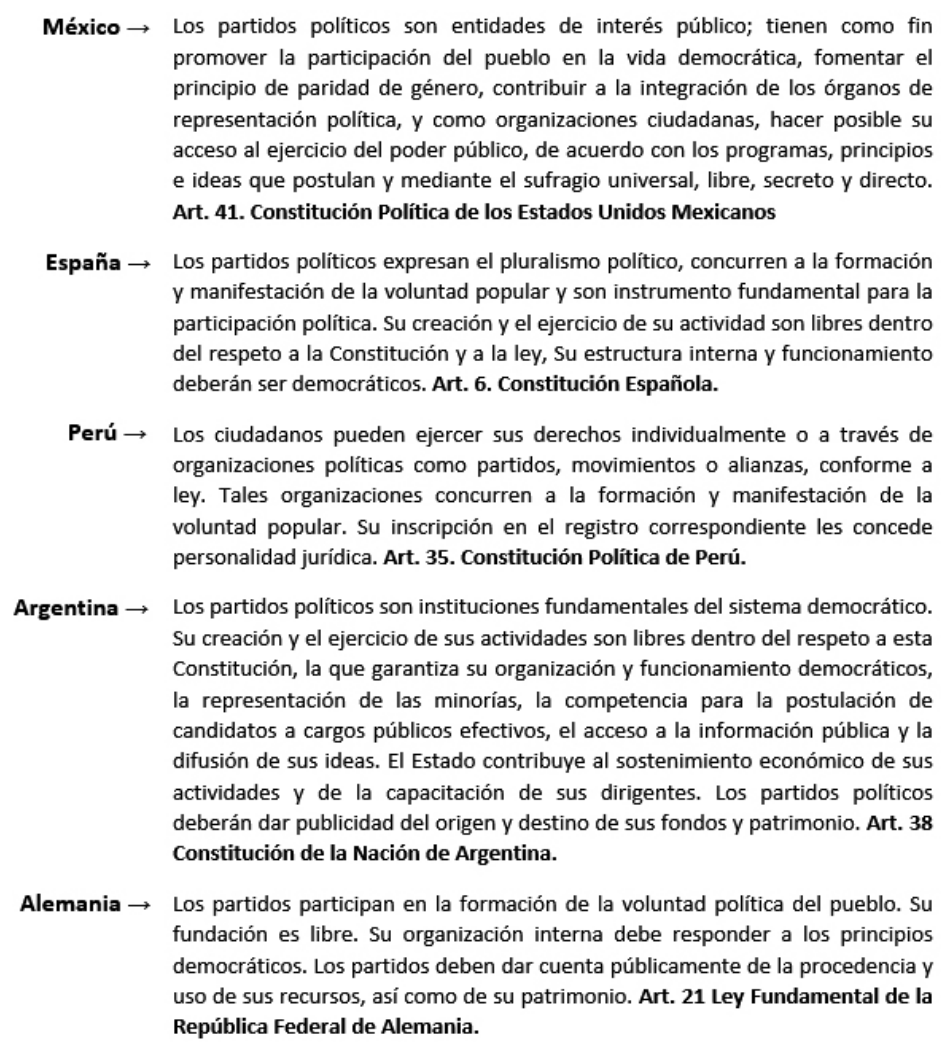
promover la participación del pueblo en la vida democrática, fomentar el principio de paridad de género, contribuir a la integración de los órganos de representación política, y como organizaciones ciudadanas, hacer posible su acceso al ejercicio del poder público, de acuerdo con los programas, principios e ideas que postulan y mediante el sufragio universal, libre, secreto y directo. Art. 41. Constitución Política de los Estados Unidos Mexicanos

España $\rightarrow$ Los partidos políticos expresan el pluralismo político, concurren a la formación y manifestación de la voluntad popular y son instrumento fundamental para la participación política. Su creación y el ejercicio de su actividad son libres dentro del respeto a la Constitución y a la ley, Su estructura interna y funcionamiento deberán ser democráticos. Art. 6. Constitución Española.

Perú $\rightarrow \quad$ Los ciudadanos pueden ejercer sus derechos individualmente o a través de organizaciones políticas como partidos, movimientos o alianzas, conforme a ley. Tales organizaciones concurren a la formación y manifestación de la voluntad popular. Su inscripción en el registro correspondiente les concede personalidad jurídica. Art. 35. Constitución Política de Perú.

Argentina $\rightarrow$ Los partidos políticos son instituciones fundamentales del sistema democrático. Su creación y el ejercicio de sus actividades son libres dentro del respeto a esta Constitución, la que garantiza su organización y funcionamiento democráticos, la representación de las minorías, la competencia para la postulación de candidatos a cargos públicos efectivos, el acceso a la información pública y la difusión de sus ideas. El Estado contribuye al sostenimiento económico de sus actividades y de la capacitación de sus dirigentes. Los partidos políticos deberán dar publicidad del origen y destino de sus fondos y patrimonio. Art. 38 Constitución de la Nación de Argentina.

Alemania $\rightarrow$ Los partidos participan en la formación de la voluntad política del pueblo. Su fundación es libre. Su organización interna debe responder a los principios democráticos. Los partidos deben dar cuenta públicamente de la procedencia y uso de sus recursos, así como de su patrimonio. Art. 21 Ley Fundamental de la República Federal de Alemania.

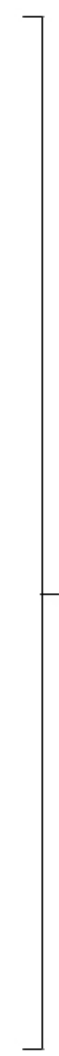

Los partidos políticos son instituciones fundamentales del sistema democrático, expresan el pluralismo políticos, participan en la formación de la voluntad política del pueblo; contribuyen a la integración de los órganos de representación política.

Fuente: Constitución Política de México, España, Perú, Argentina y Alemania, vigentes en el 2018. 


\section{Caso México - Argentina: partidos políticos en la Constitución}

Como vimos anteriormente, la base legal de los partidos políticos se encuentra en la Constitución, centrándonos en México y Argentina, objeto del presente estudio.

\section{Ilustración 3. Recepción constitucional teórica de los partidos políticos}

\section{Comparativo de los elementos teóricos definitorios de un partido político en las constituciones de México y Argentina}

\begin{tabular}{|l|}
\hline \multicolumn{1}{|c|}{ México } \\
\hline • Entidades de interés \\
público. \\
- Tienen como fin pro- \\
mover la participación \\
del pueblo en la vida \\
democrática. \\
- Solo los ciudadanos \\
podrán formar partidos \\
políticos y afiliarse a ellos: \\
por tanto, quedan prohibi- \\
das las intervenciones de \\
organizaciones. \\
- La ley garantizará que los \\
partidos políticos naciona- \\
les tangan financiamiento, \\
debiendo garantizar que \\
los recursos públicos pre- \\
valizcan sobre los de ori- \\
gen privado.
\end{tabular}

\begin{tabular}{|l|}
\hline \multicolumn{1}{|c|}{ Argentina } \\
\hline • Instituciones funda- \\
mentales del sistema \\
democrático. \\
• La Constitución garan- \\
tiza su organización y \\
funcionamiento democrá- \\
ticos, la representación de \\
las minorías. \\
• El Estado contribuya al \\
sostenimiento económico. \\
• Deberán dar publicidad \\
del origen y destino de sus \\
fondos y patrimonio. \\
\end{tabular}

Fuente: Constitución Política Mexicana y Argentina, vigentes en el 2018.

Actualmente existen 10 partidos políticos en México. En los últimos 10 años en Argentina, los partidos de orden nacional han oscilado entre 30 y 45, mientras los partidos de distrito lo han hecho entre 500 y 650 de acuerdo con los parámetros de la Ley Orgánica de los Partidos Políticos (Ley No. 23.298) (INE, 2021; Gobierno de Argentina, 2021). En ambos casos, su principal fuente de financiamiento se compone por las prerrogativas públicas que se otorgan a través de los presupuestos generales de los respectivos Estados. 
FINANCIAMIENTO PÚBLICO PARA PARTIDOS POLÍTICOS Y SU REFLEJO EN EL DESARROLLO NACIONAL, PERSPECTIVA COMPARADA ARgENTINA - MÉXiCO - JosÉ LUIS LEAL ESPINOZA,

\section{Financiamiento}

\section{III.1. Financiamiento público}

La expresión financiamiento público se utiliza en relación con el empleo de fondos públicos en beneficio de los partidos y las campañas. Este puede hacerse de manera directa, transfiriendo a unos u otros dinero del presupuesto nacional, o de manera indirecta, mediante la concesión de ventaja, prerrogativas, aportes en especie o subvenciones a favor de los partidos o de las campañas electorales, $o$ como incentivo para las donaciones privadas (De la Calle, 2004, p. 23).

Sobre todo, y como menciona también Pilar del Castillo (1997), para la situación española, los grupos en el Congreso de los Diputados coincidían en que los resultados obtenidos marcaran la distribución de subvenciones públicas, así como la necesidad de la representación parlamentaria para acceder a los mismos.

Jiménez (2005) explica el nacimiento del financiamiento público, señalando que con el tiempo quedó claro que los partidos necesitan recursos que sea posible canalizar sus postulados y principios ideológicos, para formar políticamente a sus afiliados en inducirlos a la participación activa en los procesos electorales y para apoyar a sus candidatos en la realización de sus campañas políticas, sobre todo para estar en condiciones de ofrecer a sus miembros la posibilidad de llegar al poder mediante el voto ciudadano. Los partidos necesitan recursos y apoyos, es decir, requieren el financiamiento de sus actividades.

En países con complicados momentos políticos como lo fueron México y Argentina, Díaz Santana (2019) nos recuerda que, en la pluralidad caótica de la práctica política, América Latina en lo general ha tenido momentos convulsos en los que el financiamiento público fortaleció y sentó las bases de la transición democrática la constituirse como un factor fundamental para la construcción de sistemas plurales de partidos.

De la Calle (2004) señala que el objetivo central que sirve de fundamento para el financiamiento público es dotar de un mínimo de recursos a todas las organizaciones políticas, una especie de mínimo común denominador que mitigue los privilegios que se derivan de una financiación privada exclusiva. Por su parte, Aparicio, Pérez y Pérez (2007) señalan que el financiamiento encuentra su razón de ser primero en el hecho de que trabaja para equilibrar las condiciones de competencia entre el partido en el poder y los partidos de oposición. Segundo, disminuir la influencia de grupos de interés en el financiamiento de campañas y la toma de decisiones de los partidos y los políticos. Tercero, proveer una base mínima de 
recursos para que partidos nuevos o relativamente pequeños puedan organizarse y sobrevivir en la contienda electoral.

Aquellos que defienden el financiamiento público argumentan principalmente, como lo hace García (2007), que con regulación se buscar eliminar los acuerdos quid pro quo, fomentar la transparencia de los procesos electorales y abaratar el coste de las campañas.

De acuerdo con lo presentado en el periódico El País por Leandro Querido, titular de Transparencia Electoral, la última campaña presidencial, en 2015, costó casi diez veces más que el máximo estipulado, 172 millones de pesos (unos 18 millones de dólares en ese momento) en Argentina (Centenera, 2017, pár. 4), mientras que en México se destinaron 2148 millones de pesos para partidos en 2018, además de 42 millones para candidatos independientes (Navarro, 2018).

\section{III.1.1. Ventajas y desventajas}

Uno de los principales inconvenientes del financiamiento público de acuerdo con Katz y Mair (1995) es el grado de dependencia al Estado que desarrollan los partidos políticos; en contrapartida, Scarrow (2009) argumenta que es indispensable restringir el financiamiento privado, toda vez que se ejercería sobre los resultados electorales la influencia de los donantes.

De hecho, comprendiendo la gravedad del dinero privado en las elecciones, información obtenida por la OCDE (2016) señala que 74\% de los países han implementado regulaciones para prohibir donaciones a partidos políticos de corporaciones que tengan contratos gubernamentales o compartan propiedades parciales con el gobierno.

Diversos autores coinciden que el financiamiento público es una moneda de dos caras, si bien por un lado favorecen la actividad partidista, dada la fórmula de repartición y la cantidad de recursos otorgados, se aleja de la equidad, de tal forma que en opinión de De la Calle (2004), Bernal (s.f.) y Aparicio, Pérez y Pérez (2007), el financiamiento público presenta las siguientes:

\section{Ventajas}

- Fortalece la autonomía de los políticos.

- Protege la igualdad política de oportunidad y competencia electoral. 
- Permite sobrevivir en un entorno en el cual se ha hecho más costoso difundir un mensaje y atraer los votos de sociedades más plurales.

- Transparencia en el origen de los recursos.

- Independencia de los partidos políticos respecto de cualquier interés ajeno a los mismos.

- Condiciones adecuadas de equidad en la competencia electoral.

- Evita la tentación de acudir a fuentes ilegitimas de financiamiento.

\section{Desventajas}

- Los partidos políticos pueden volverse excesivamente dependientes del erario público.

- Disminuyen los incentivos para que los partidos se mantengan tan cerca del electorado como lo harían sin dicho financiamiento.

- El financiamiento público puede premiar o castigar a cierto tipo de partidos.

- Los subsidios no eliminan la corrupción, ya que las fuentes privadas e ilegales de financiamiento siguen existiendo.

- Para los partidos es más fácil obtener dinero sin hacer un esfuerzo por movilizar a los votantes.

- El dinero público provoca que el sistema de partidos se cierre debido a que los legisladores tienen incentivos para cambiar las reglas a su favor, otorgándose más dinero y elevando las barreras a la entrada.

- Desvinculación de los partidos políticos respecto de la sociedad.

- Burocratización de los partidos políticos.

- Gasto desmesurado por parte de los partidos políticos respecto de los recursos provenientes del erario público.

- Absoluta dependencia por parte de los partidos políticos respecto de los recursos provenientes del estado.

- Descontento popular debido al excesivo monto proveniente de la recaudación fiscal destinado al sostenimiento de los partidos políticos. 
- Genera la sed inapagable de dinero.

- Aportaciones de grupos poderosos entregados con el objeto de incidir posteriormente en el gobierno electo.

- Concentración en la toma de decisiones internas de los partidos.

- Genera una dependencia económica de los partidos de los dineros oficiales.

- Se debilitan la relación entre la organización formal y los prosélitos, dado que los aportes son también una forma de participación.

En este orden de ideas, compartimos la visión que la ex magistrada Pilar del Castillo Vera (1983) establece claramente dentro de los objetivos para la reforma de la legislación sobre la financiación de partidos políticos, así como los pros y contras respecto de su financiamiento y regulación en las reglas que imperan en la naturaleza jurídica electoral a partir de la institucionalización partidista dentro de la vida democrática.

\section{III.2. Fórmula de distribución}

En esta sección, es importante resaltar la complejidad política de ambos países, puesto que, como veremos a continuación, la forma de financiamiento en ambos se reparte desde los ámbitos público y privado, además de que dependen de sus particulares figuras, sobre todo de la distinción de la carencia de "segunda vuelta" en México, por lo que marca una línea de distinción importante pero no alejada de las concepciones de otorgamiento de los recursos.

Bajo el supuesto de Jiménez (2005), el principio fundamental que ha de regir el sistema de financiación de los partidos es el de igualdad de oportunidades entre los mismos, al decidir sobre los criterios para distribuir la financiación estatal directa o indirecta; De la Calle (2004) señala que debe considerarse que se puede favorecer a los partidos previamente establecidos si se establece un sistema basado exclusivamente en el número de votos, aunque aparentemente más democrático, en cambio, un esquema rígidamente igualitario, por otro lado, en cuanto nos recoge los resultados de las decisiones populares, termina también generando distorsiones. 
La legislación mexicana le otorga un amplio espacio al rubro de partidos políticos; su fundamento nace en la Carta Magna, artículo 41: "Los partidos políticos tienen como fin promover la participación del pueblo en la vida democrática, contribuir a la integración de los órganos de representación política y como organizaciones de ciudadanos (...). La ley garantizará que los partidos políticos nacionales cuenten de manera equitativa con elementos para llevar a cabo sus actividades (...)".

El financiamiento que obtienen los partidos políticos es mixto, aunque principalmente viene del erario público, y se divide de tal forma que los partidos obtienen recursos, aún y cuando no hay elección, tal como se muestra en las ilustraciones 4 y 5 .

Ilustración 4. Financiamiento a partidos políticos en México

\section{Financiamiento de partidos políticos en México}

\begin{tabular}{|c|c|c|c|}
\hline & & & Privado \\
\hline $\begin{array}{l}\begin{array}{c}\text { Actvidades ordinarias } \\
\text { permanentes }\end{array} \\
30 \% \text { distribuido } \\
\text { entre los pasrtidos } \\
\text { políticos de forma } \\
\text { igualitaria. } \\
70 \% \text { distribuido de } \\
\text { acuerdo con el } \\
\text { porcentaje de votos } \\
\text { que hubieran } \\
\text { obtenido en la } \\
\text { elección } \\
\text { diputados de } \\
\text { inmediata anterior. }\end{array}$ & $\begin{array}{l}50 \% \text { (de actividades } \\
\text { ordinarias en ese } \\
\text { mismo año), cuando } \\
\text { se elije Presidente de } \\
\text { la República, } \\
\text { Senadores } \\
\text { Diputados Federales. } \\
30 \% \text { (de las } \\
\text { actividades } \\
\text { ordinarias en ese } \\
\text { mismo año), cuando } \\
\text { sólo se elijan } \\
\text { Diputados Federales. }\end{array}$ & $\begin{array}{l}\text { 3\% de las actividades } \\
\text { ordinarias. } \\
30 \% \text { distribuido entre } \\
\text { los partidos políticos } \\
\text { en forma igualitaria. } \\
70 \% \text { distribuido con } \\
\text { el porcentaje de } \\
\text { votos que hubieren } \\
\text { obtenido en la } \\
\text { elección } \\
\text { diputados inmediata } \\
\text { anterior. }\end{array}$ & $\begin{array}{l}\text { El Consejo General } \\
\text { determinará el } \\
\text { tope de gastos } \\
\text { equivalente al diez } \\
\text { por ciento del } \\
\text { establecido para las } \\
\text { campañas } \\
\text { inmediatas } \\
\text { anteriores, según la } \\
\text { elección de que se } \\
\text { trate. }\end{array}$ \\
\hline
\end{tabular}

Fuente: Constitución Política de México, vigente en el 2018. 


\section{Ilustración 5. Financiamiento a partidos políticos en Argentina}

\section{Financiamiento de partidos políticos en Argentina}

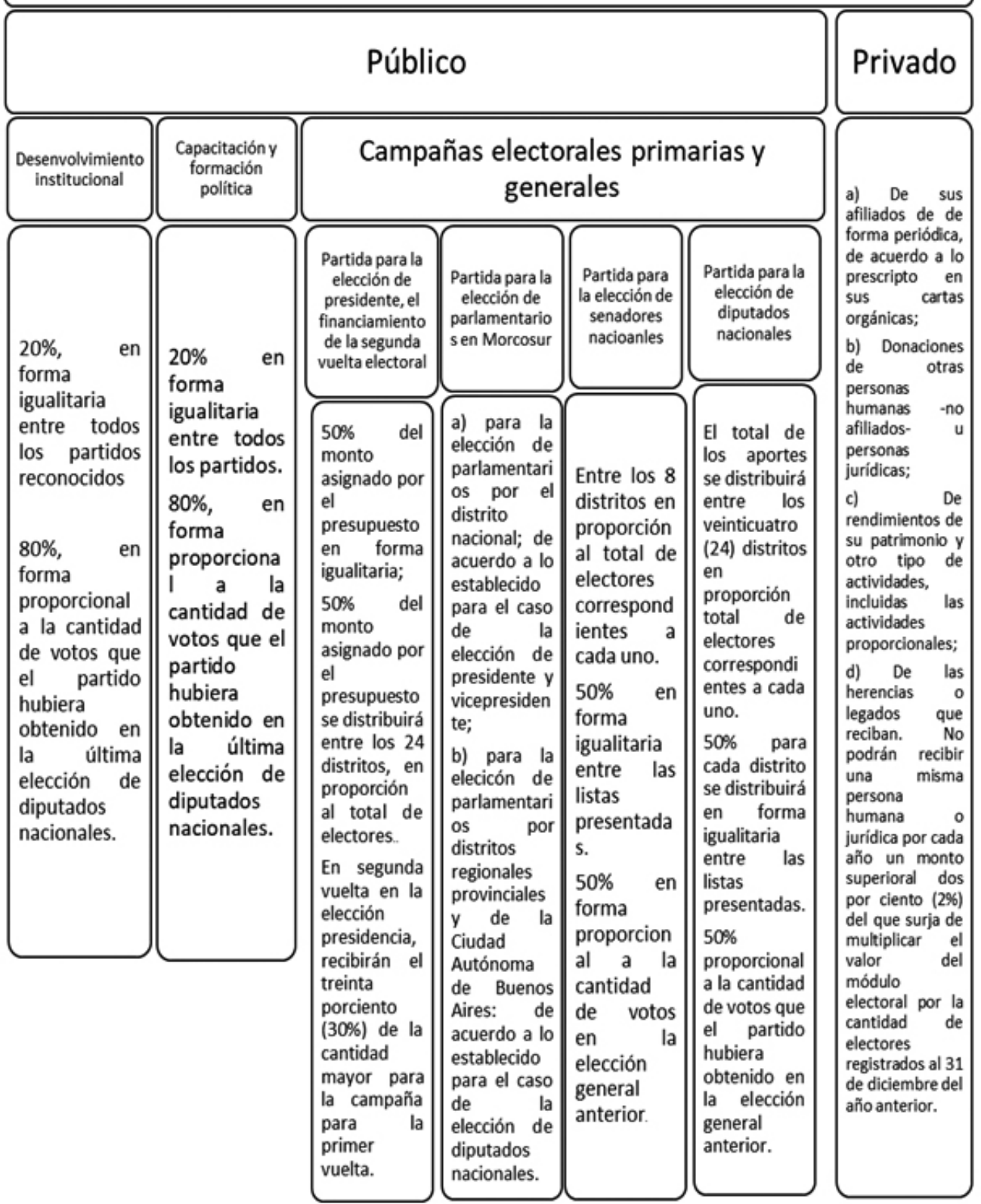

Fuente: Constitución Política de Argentina, vigente en el 2018. 


\section{Metodología}

\section{IV.1. Investigación cualitativa-deductiva en materia de los sistemas e instituciones políticas (partidos políticos) como elementos de desarrollo democrático en México y Argentina}

El presente estudio toma su relevancia al buscar identificar y establecer si los medios de control que al día de hoy se encuentran vigentes dentro del marco normativo resultan eficaces para establecer el modelo de fiscalización de los partidos políticos en México, en lo particular, y en Argentina, en lo general, bajo la aplicación de un modelo constructivista-comparado.

Poder lograr la identificación de estrategias legales que permitan brindar los servicios públicos mediante sistemas que controlen y regulen de una manera más eficaz la actuación de los partidos políticos, a fin de mejorar en la administración pública y los servicios que brindan, una vez que estos alcanzan la responsabilidad de gobernar.

Los alcances del presente trabajo son preponderantemente descriptivos y correlativos. Lo anterior, toda vez que partimos de conocer la existencia del sistema de partidos políticos y su financiamiento públicos en México y Argentina, y el marco normativo construido para contrarrestarlo; sin embargo, dada la amplitud de su ámbito de variables que lo conforman en sus elementos constitutivos y características, es imprescindible partir de supuestos descriptivos que nos ayuden a comprender de mejor manera sus componentes, para adquirir el conocimiento necesario que permita el entendimiento del problema. Además, resulta necesario establecer elementos que nos permitan predecir las relaciones existentes entre las variables que dan origen a la transparencia y rendición de cuentas, para estar en posibilidades de entender la forma en que interactúan entre sí y poder determinar el funcionamiento del fenómeno de la corrupción en la prestación de los servicios públicos a cargo de las instituciones y asociaciones políticas, logrando así establecer la evolución que de este concepto se ha tenido en el estado de derecho, desde su inserción, regulación y control en el marco normativo mexicano.

El diseño de los métodos a utilizar ha sido definido en base a las necesidades de estudio, tomando en consideración los métodos de investigación más habituales. Partiendo de su referencia, se decidirán los pasos y actividades a planificar para definir las técnicas que ayuden al análisis de los datos.

Se abordará un diseño de investigación cualitativo el cual, "es una investigación desde dentro" (Valmaseda, 2016, p. 105), que supone una preponderancia dé lo individual y subjetivo. Su concepción de la realidad. 
Específicamente abarcaremos dos tipos de investigación: en primera instancia, el derecho comparado. Para ser más precisos, el "Derecho comparado abstracto o especulativo. Esta rama también se designa como derecho comparado puro y utiliza la comparación para ensanchar la suma total de los conocimientos jurídicos" (Morineau 1997, p. 20).

René David dice que el papel del derecho comparado es parecido al de la historia; dándole al estudioso del derecho nacional la perspectiva necesaria para tener una visión adecuada de los puntos fundamentales y la evolución de su derecho, y permitiéndole, por otro lado, un planteamiento más exacto de los posibles problemas que se presenten, para lograr una mejor solución a las cuestiones jurídicas que se deban resolver. No se puede hablar de una cultura jurídica sobre la base exclusiva del derecho nacional. Pretender limitar la ciencia jurídica a fronteras nacionales y querer exponerla o perfeccionarla sin tomar en cuenta tanto la teoría como las prácticas extranjeras es limitar la potencialidad del jurista, puesto que el derecho nacional, y más hoy en día, está influenciado tanto por fenómenos y circunstancias internas como externas. El conocimiento de otros derechos; la unificación de derechos (David y Jauffret-Spinosi, 2002, p. 4).

En segunda instancia utilizaremos el método deductivo, el cual consiste en exponer premisas y/o preposiciones para extraer conclusiones lógicas, La deducción permite establecer un vínculo de unión entre teoría y observación y permite deducir a partir de la teoría los fenómenos objeto de observación (Neuman, 1991, p. 181).

Para ahondar más acerca de este método es importante comprender que las conclusiones deductivas son necesariamente inferencias hechas a partir de un conocimiento que ya existía. En consecuencia, la indagación científica no puede efectuarse solo por medio del razonamiento deductivo, pues es difícil establecer la verdad universal de muchos enunciados que tratan de fenómenos científicos. El razonamiento deductivo puede organizar lo que ya se conoce y señalar nuevas relaciones conforme pasa de lo general a lo específico, pero sin que llegue a constituir una fuente de nuevas verdades.

\section{Resultados}

\section{V.1. El reflejo en el desarrollo: ¿Qué nos dice el financiamiento del desarrollo en México y Argentina?}

De forma general, los partidos políticos a través de su ideología, estatutos y compromisos, establecen una serie de propuestas tendientes todas a impulsar el desarrollo integral del Estado, siendo la propuesta más idónea, popular o mejor planteada la que se gane el apoyo ciudadano, reflejando en el voto obtenido en las elecciones. 
De tal suerte que, además del papel fundamental que ejercen los partidos políticos como garantes del sistema democrático, también deberían ser los conductos para que quienes lleguen al poder atiendan tanto la ideología como los compromisos adquiridos con el electorado.

Por tanto, se entiende que, si se vota por tal o cual partido, es porque logro convencer al electorado de que su propuesta para mejorar la situación del país es la mejor; no obstante, y pese al costo económico que para el Estado tiene mantener este sistema de partidos políticos, los índices de crecimiento, confianza en las instituciones y en general la calidad de vida de la ciudadanía no ha mejorado.

\section{V.2. Índice de participación electoral}

\section{V.2.1. Confianza en las instituciones}

Para el siguiente apartado y a fin de establecer la situación por la que se atraviesa tanto en México, como en Argentina, se utiliza la información de Corporación Latinobarómetro (2018).

\section{Ilustración 6. Confianza en los partidos políticos en Latinoamérica}
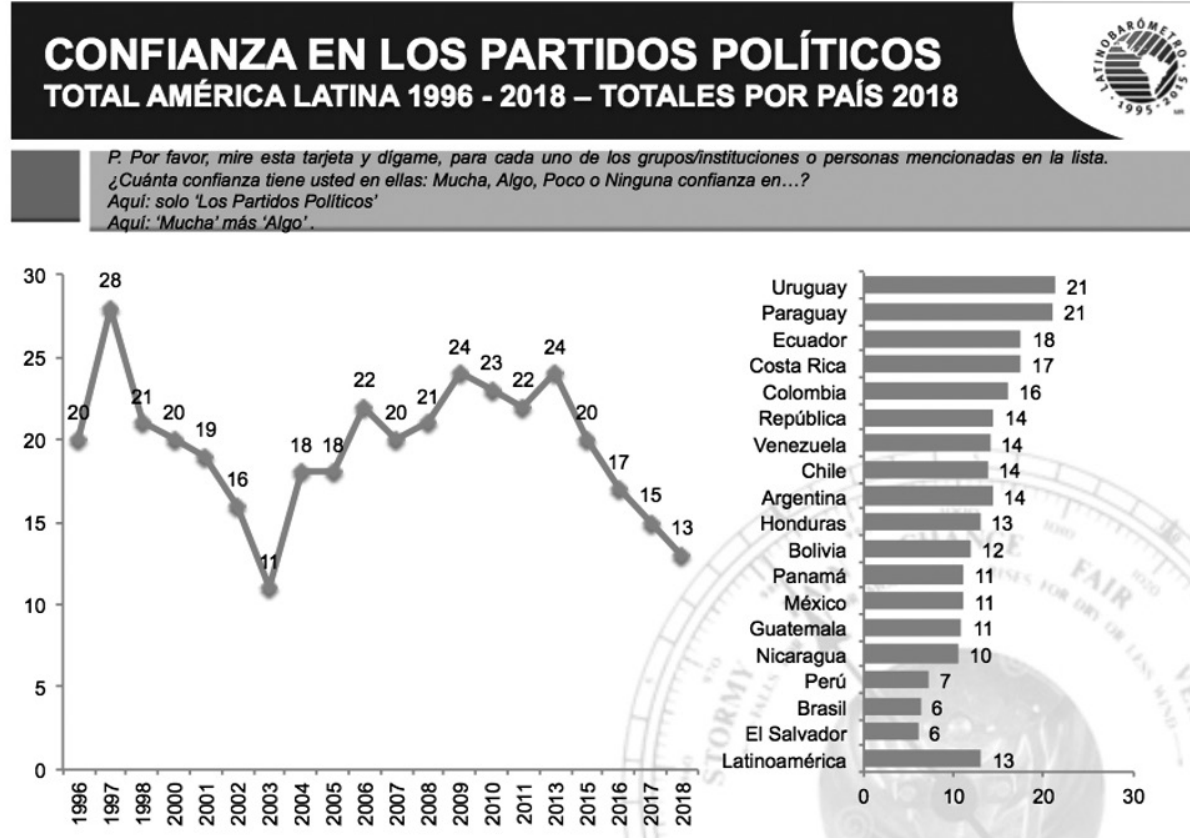

Fuente: Informe Latinobarómetro (2018, p. 53). 
Es notorio que los índices de confianza en los partidos políticos han descendido en los últimos años en América Latina, sobre todo en países como México que actualmente se encuentran debajo de la media de aceptación, en contraparte a Argentina que supera por un punto la media de aceptación. Este es un factor vital para las instituciones democráticas en el desarrollo nacional.

\section{Ilustración 7. Democracia en Latinoamérica}

\section{UNA DEMOCRACIA CON GRANDES PROBLEMAS}

\section{TOTAL AMÉRICA LATINA 2013 - 2018 - TOTALES POR PAÍS 2018}

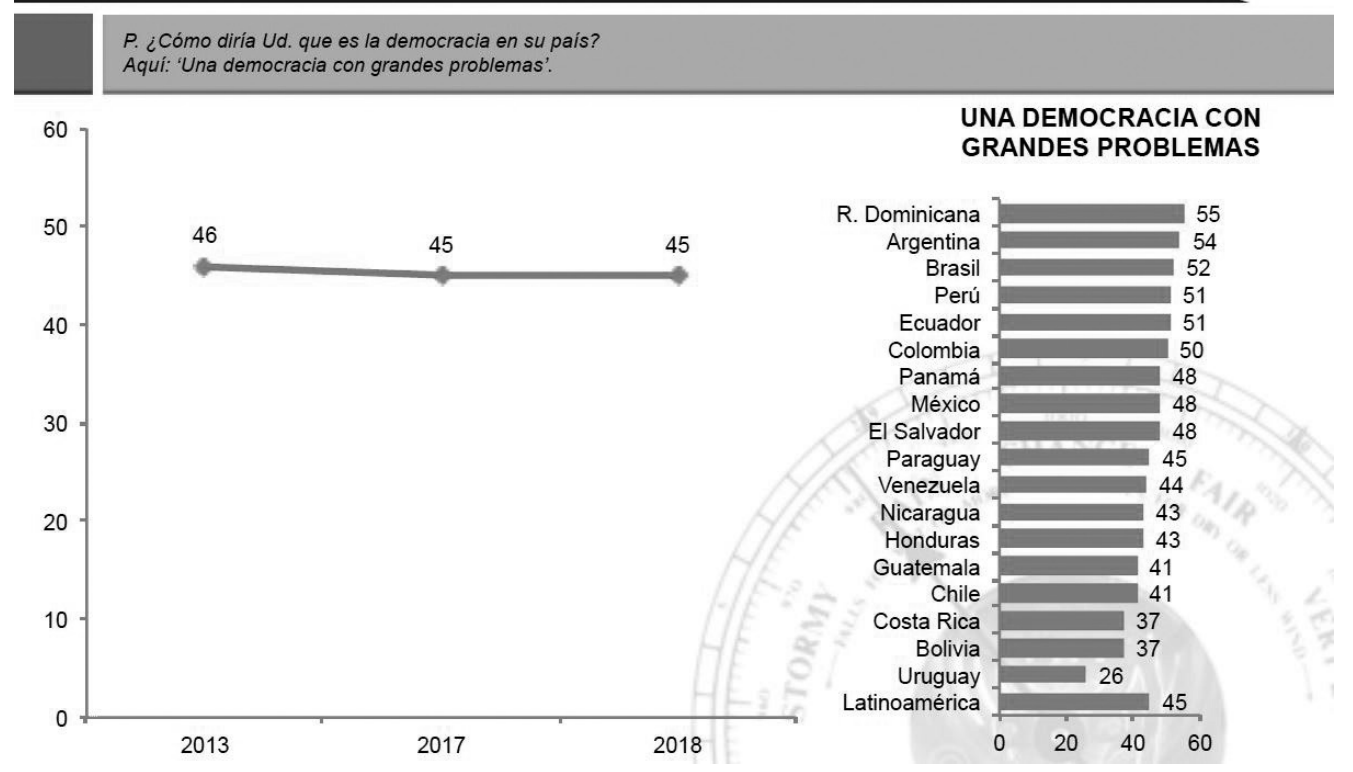

Fuente: Informe Latinobarómetro (2018, p. 34).

Tanto Argentina como México tienen una percepción casi mayoritaria de una democracia en problemas, lo que puede relacionarse con la confianza en los partidos políticos para determinar su influencia en la calidad de las instituciones, así como determinar a futuro los financiamientos para estas. 


\section{V.2.2. Nivel de pobreza}

\section{Ilustración 8. Índice de Desigualdad en Latinoamérica}

América Latina (18 paises): indice de desigualdad de Gini, 2002-2017ª

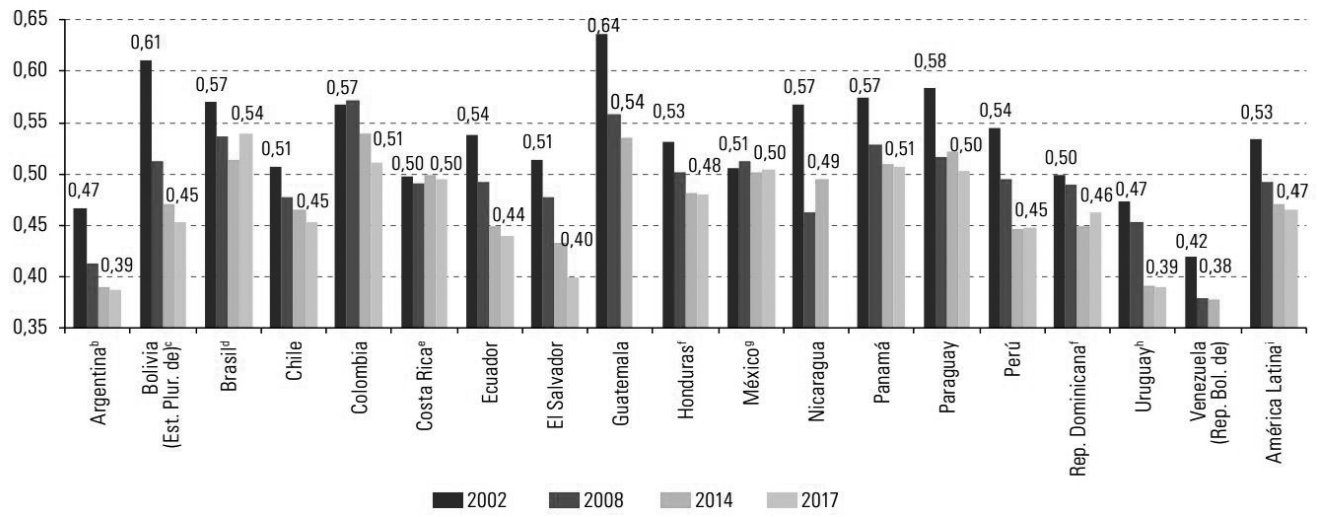

Fuente: Comisión Económica para América Latina y el Caribe (CEPAL), sobre la base de Banco de Datos de Encuestas de Hogares (BADEHOG). Las cifras por países representadas en el gráfico pueden verse en el cuadro I.A1.1 en el anexo del capítulo I.

a El índice de Gini se calculó considerando los ingresos iguales a 0.

b Total urbano.

${ }^{c}$ Cifras de 2017 corresponden a 2015.

${ }^{d}$ Cifras de 2017 no comparables con las de años anteriores.

e Cifras a partir de 2010 no comparables con las de años anteriores.

${ }^{\dagger}$ Cifras de 2017 corresponden a 2016.

g Cifras de 2016 estimadas sobre la base del "Modelo Estadístico 2016 para la continuidad del MCS-ENIGH".

${ }^{\mathrm{h}}$ Las cifras de 2002 corresponden al área urbana.

i Promedio construido sobre la base de información del año más cercano disponible para cada uno de los 18 países.

Fuente: CEPAL (2018, p. 18). 


\section{Ilustración 9. Índice de situación económica en Latinoamérica}

\section{NETO DE LA SITUACIÓN ECONÓMICA ACTUAL DEL PAÍS DIFERENCIAS NETAS POR PAÍS 2018}

P. ¿Cómo calificaría en general la situación económica actual del pais? Diría Ud. que es Muy buena, Buena, Regular, Mala o Muy mala?

Aquí: 'Muy buena' más 'Buena'y 'Mala' más 'Muy mala'.

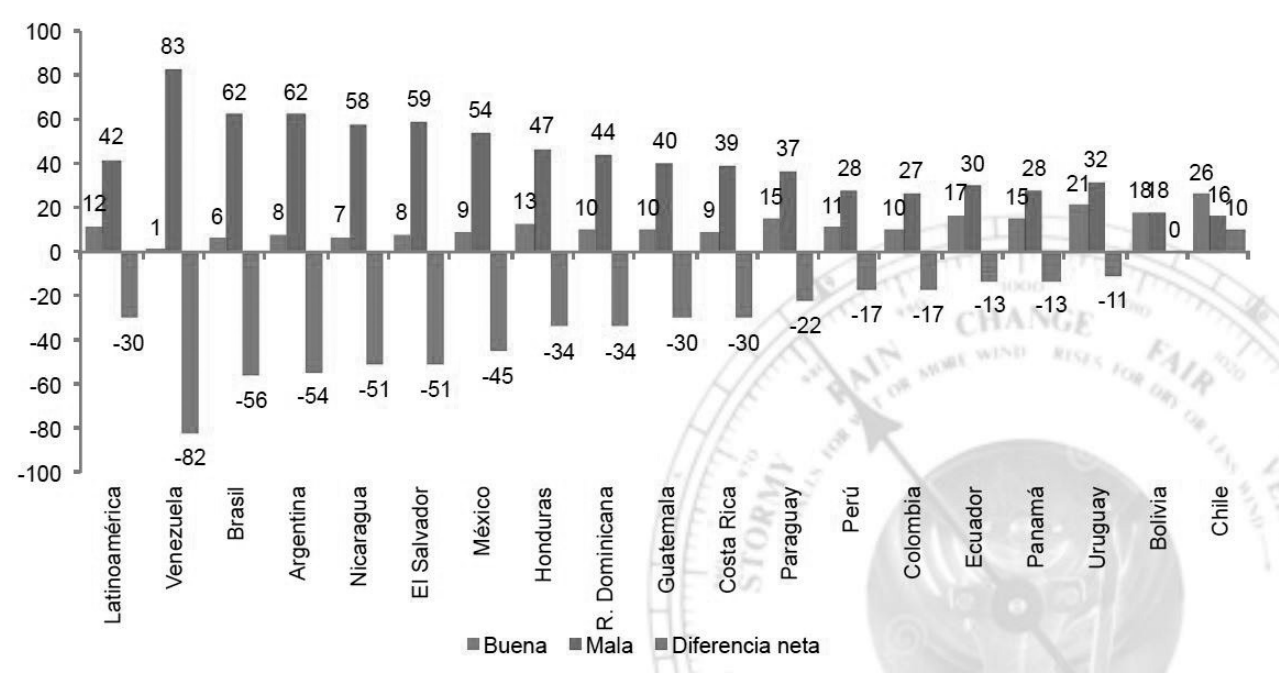

Fuente: Informe Latinobarómetro (2018, p. 9).

La descripción de la situación de desigualdad y la percepción de la situación económica en ambos países concuerda con la percepción de la confianza hacia los partidos y el desempeño de las instituciones en la promoción de la percepción de democracias que, para estos países, aparecen como mayormente problemáticas. Aunado a ello, en la siguiente ilustración (10) se describe un avance hacia el progreso económico de manera progresiva pero pausada. 


\section{V.2.3. Nivel de crecimiento económico}

\section{Ilustración 10. Índice de progreso en Latinoamérica}

\section{IMAGEN DE PROGRESO EN EL PAÍS TOTALES POR PAIS 2018}

P. ¿Diría Ud. que este país...? Está progresando, Está estancado, Está en retroceso.

Aquil: 'Está progresando'

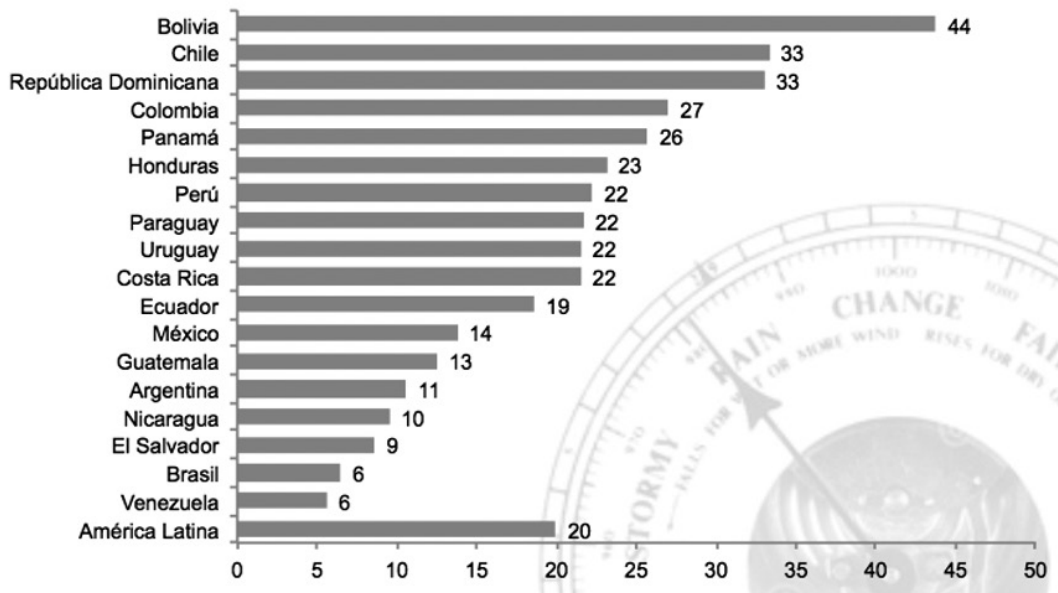

Fuente: Informe Latinobarómetro (2018, p. 5)

\section{Conclusiones}

El objeto principal de la presente investigación fue exponer la relación que existe entre los partidos políticos, su sistema de financiamiento y la percepción que se tiene sobre su funcionamiento y el crecimiento integral del Estado nación.

En primera instancia, se realizó una comparación sobre los sistemas partidistas de Argentina y México, denotando como primera diferencia el número de partidos que se tienen en cada país, seguido de la dependencia que estos partidos políticos tienen del Estado.

Como ha quedado claro, si bien es cierto los partidos políticos fungen como un elemento primordial del sistema democrático, es cierto esto no los exime de las responsabilidades que tienen para con sus militantes, electores y por supuesto para el Estado, responsabilidades que se ven reflejadas en la confianza de la ciudadanía y sobre todo en el crecimiento integral del Estado. 
Tanto en Argentina como en México, es indudable el gran esfuerzo económico que realiza para sostener a estas instituciones democráticas. El financiamiento público constituye la base en la que se fundan, trabajan y se desarrollan los partidos políticos; no obstante, este financiamiento público no hace ruido para darle resultados a la ciudadanía, que de acuerdo con los informes antes presentados no gozan de su confianza. A pesar de que México tiene un número menor de partidos políticos, es innegable el hecho de que el financiamiento público es indispensable para los partidos políticos en ambos países, aun cuando se han instalado controles fiscales, y de transparencia en ambos.

Se observa un desgaste progresivo en el incumplimiento de las expectativas ciudadanas acerca de los partidos políticos, los cuales deben significarse desde su sentido primario, tal como lo exponen los doctrinarios antes citados, como el vínculo organizado entre las legítimas demandas sociales y la eficacia de las políticas públicas que el Estado debe observar a través de las expresiones de la mayoría que representa la semiótica de los citados partidos.

\section{Ilustración 10. Actuación de los partidos políticos}

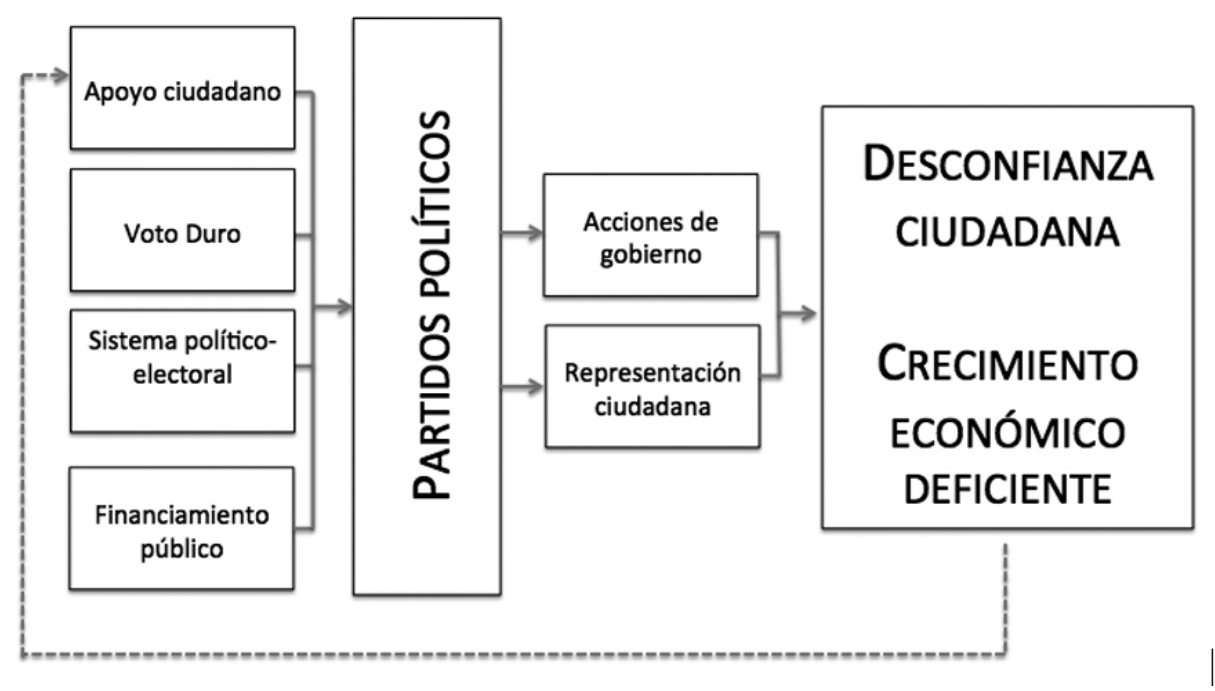

Fuente: elaboración propia con base en el marco teórico expuesto.

Hasta el momento, estudiosos de la materia refieren que no hay un sistema de gobierno mejor que el democrático, y la falla de los partidos políticos no implica la falla del sistema democrático, pero si es un claro indicador de que algo no se está realizando de forma correcta. Mientras que el Estado continué gastando recursos económicos en partidos políticos que no cumplen con el compromiso de 
FINANCIAMIENTO PÚBLICO PARA PARTIDOS POLÍTICOS Y SU REFLEJO EN EL DESARROLLO NACIONAL, PERSPECTIVA COMPARADA ARgENTINA - MÉXICO - JosÉ LUIS LEAL EsPinOZA,

generar una mejor calidad de vida para la ciudadanía, seguiremos estando frente a un círculo vicioso del cual no será posible salir, por lo menos no sin una reforma estructural al sistema de partidos.

México y Argentina comparten ciertas características comparables; sin embargo, es justo reconocer que ambas naciones enfrentan problemas intrínsecos a su sistema político electoral. Una diferencia palpable es la configuración del Poder Legislativo: mientras en México está conformado por entre cinco y siete grupos legislativos, en Argentina la gran cantidad de partidos obligan a trabajar en coalición o en bloque. Ello implica, por supuesto, consenso, diálogo y sobre todo la aceptación de diversas ideologías políticas, privilegiando un interés supremo.

\section{Bibliografía}

Aparicio, F.; Pérez, J. y Pérez, J. (2007). Financiamiento Público a Partidos Políticos. Manuscrito no publicado. México: División de Estudios Políticos.

Basave, A. (1982). Partidos políticos y sistemas electorales. México: UNAM.

Cárdenas, R. (2012). Democracia y partidos políticos. México: Instituto Federal Electoral.

Castillo Vera, P. (1983). La financiación de partidos y candidatos en las democracias occidentales. Madrid: CIS.

Centenera, M. (2017, junio 27). La financiación electoral, un agujero negro en Argentina. El País, Argentina. Recuperado de: https://elpais.com/internacional/2017/06/27/argentina/1498594031_477519.html

David, R. y Jauffret-Spinosi, C. (2010). Los grandes sistemas jurídicos contemporáneos. UNAM.

De la Calle, H. (2004). Financiamiento político: público, privado, mixto. En D. Zovatto y S. Griner (eds.), De las normas en las buenas prácticas. El desafío del financiamiento político en América Latina. San José: Instituto internacional para la democracia y la asistencia electoral.

Del Castillo, P. (1997). La financiación de los partidos políticos: 1977-1997. Revista De Las Cortes Generales, (41), 153-167. https://doi.org/10.33426/rcg/1997/ $41 / 973$

Díaz Santana, H. (2019). Financiamiento público de partidos en México y su propuesta de reforma. Revista Mexicana de Derecho Electoral, No 15-16, enero, (p. 105-136). Ciudad de México. 
Duverger, M. (2002). Los Partidos Políticos (18a ed.). México: Fondo de Cultura Económica.

Fernández, J. (1985). Panorama del derecho mexicano. México: Mc Graw Hill.

García, R. (2006). Introducción a los sistemas complejos. México: Gedisa.

García Viñuela, E. (2007). La regulación del dinero político. Reis. Revista Española de Investigaciones Sociológicas, 1, Centro de Investigaciones Sociológicas. Madrid. Recuperado de: https://www.redalyc.org/pdf/997/99715251003.pdf

Gobierno de Argentina (2021). Partidos Políticos. Recuperado de: https://www. argentina.gob.ar/interior/observatorioelectoral/partidospoliticos

Instituto Nacional Electoral. INE. (2021). Partidos políticos nacionales. Recuperado de: https://www.ine.mx/actores-politicos/partidos-politicos-nacionales/

Jiménez, F. (2005). Financiamiento a Partidos Políticos y Teoría de Juegos (p. 150). México.

Katz, R. S. y Mair, P. (1995). Changing Modes of Party Organization and Party Democracy: The Emergence of the Cartel Party. Party Politics, 1 (1) (pp. 5-28).

Morgan, G. (1986). Imágenes de la Organización. Madrid: Rama.

Morineau, O. (1997). Los derechos reales y el subsuelo en México. UNAM: Fondo de Cultura Económica.

Navarro, M. F. (2018). México tendrá en 2018 las elecciones más caras de su historia. Forbes México. Forbes Política. Recuperado de: https://www.forbes.com. $\mathrm{mx} /$ mexico-tendra-en-2018-las-elecciones-mas-caras-de-su-historia/

Neuman, W. (1991). Social research methods: qualitative and quantitative approaches. Boston: Allyn and Bacon.

OCDE (2016). Financing Democracy: Funding of Political Parties and Election Campaigns and the Risk of Policy Capture (1a. ed.). Paris: OECD. Public Governance Reviews. Recuperado de http:// https://read.oecd-ilibrary.org/governance/ financing-democracy_9789264249455-en

Orozco Henríquez, J. J. y Vargas Baca, C. (s/f). Regulación jurídica de los partidos políticos en México. Recuperado de: https://pdba.georgetown.edu/Parties/ Mexico/Leyes/regulacionjuridica.pdf 
Panebianco, A. (2009). Modelos de Partido: organización y poder en los partidos políticos. Alianza Editorial.

Paoli, F. (2012). Naturaleza de los partidos políticos. Revista Mexicana de Cultura Política, 1(1) (pp. 39-50).

Ruffia, Paolo Biscaretti di (1987). Derecho constitucional. Madrid: Tecnos, (trad. de Pablo Lucas Verdú de la 6a. edición italiana, actualizada con la 13a.), (pp. 216 y ss.).

Scarrow, S. E. (2007). Political Finance in Comparative Perspective. Annual Review of Political Science, 10 (1) (pp. 193-210). Estados Unidos: Annual Reviews Inc.

Valmaseda Valmaseda, J. (2016). Compendio de Metodología de la Investigación científico-educacional. México. Recuperado de: http://letras-uruguay.espaciolatino.com/aaa/valmaseda_valmaseda_jorge/Compendio\%20de\%20metodologia. pdf

\section{Legislación}

Constitución de la Nación Argentina. Recuperado de https://www.biblioteca. org.ar/libros/201250.pdf

Constitución Política de los Estados Unidos Mexicanos. Recuperado de http:// www.diputados.gob.mx/LeyesBiblio/index.htm

Ley de Financiamiento de los Partidos Políticos (Argentina). Recuperado de https://www.boletinoficial.gob.ar/detalleAviso/primera/208603/20190531

Ley General de Partidos Políticos (México). Recuperado de http://www.diputados.gob.mx/LeyesBiblio/ref/lgpp.htm

Ley Orgánica de los Partidos Políticos (Argentina). Recuperado de http://servicios.infoleg.gob.ar/infolegInternet/anexos/20000-24999/23893/texact.htm

Fecha de recepción: 29-03-2021 Fecha de aceptación: 18-09-2021 
